\title{
Anti-BCMA Antibody-drug Conjugate GSK2857916
}

National Cancer Institute

\section{Source}

National Cancer Institute. Anti-BCMA Antibody-drug Conjugate GSK2857916. NCI

Thesaurus. Code C114299.

An antibody-drug conjug ate (ADC) consisting of an afucosylated, humanized monoclonal antibody, directed against the B-cell maturation antigen (BCMA), conjug ated to the auristatin analogue and microtubule inhibitor monomethyl auristatin phenylalanine (MMAF), with potential antineoplastic activity. The anti-BCMA antibody moiety of antiBCMA ADC GSK2857916 selectively binds to the BCMA on tumor cell surfaces. Upon internalization, the MMAF moiety binds to tubulin and inhibits its polymerization, which results in G2/M phase arrest and induces tumor cell apoptosis. In addition, GSK2857916 induces antibody-dependent cellular cytotoxicity (ADCC). Altogether, this results in the inhibition of cellular proliferation in tumor cells that overexpress BCMA. BCMA, a receptor for a proliferation-inducing ligand and B-cell activating factor, is a member of the tumor necrosis factor (TNF) receptor superfamily and plays a key role in plasma survival; it is found on the surfaces of plasma cells and overexpressed on malignant plasma cells. Afucosylation of the antibody moiety increases ADCC. 